\title{
A STUDY ON TRAVEL TIME CHARACTERISTICS OF BUS SYSTEM IN DHAKA: ANALYZING DRIVERS' INTENTIONAL WAITING TIME FOR PASSENGER COLLECTION
}

\author{
Sabrena Jahan OHI ${ }^{1}$, Shinji TANAKA ${ }^{2}$, Fumihiko NAKAMURA ${ }^{3}$ and Shino MIURA 4 \\ ${ }^{1}$ Member of JSCE, Master student, Graduate School of Urban Innovation, Yokohama National University \\ (79-5 Tokiwadai, Hodogaya-ku, Yokohama 240-8501, Japan) \\ E-mail: sabrena-ohi-rt@ynu.jp \\ ${ }^{2}$ Member of JSCE, Associate Professor, Graduate School of Urban Innovation, Yokohama National University \\ (79-5 Tokiwadai, Hodogaya-ku, Yokohama 240-8501, Japan) \\ E-mail: stanaka@ynu.ac.jp \\ ${ }^{3}$ Member of JSCE, Executive Director, Vice President, Graduate School of Urban Innovation, Yokohama National \\ University (79-1 Tokiwadai, Hodogaya-ku, Yokohama 240-8501, Japan) \\ E-mail: f-naka@ynu.ac.jp \\ ${ }^{4}$ Member of JSCE, Assistant Professor, Graduate School of Urban Innovation, Yokohama National University \\ (79-5 Tokiwadai, Hodogaya-ku, Yokohama 240-8501, Japan) \\ E-mail: miurashino@ynu.ac.jp
}

\begin{abstract}
With the growing population of the megacity, Dhaka is facing severe deficiency in transportation sector. For its cheap fare, the main mode of transport for the poor is bus. Also it is the only option available as public transport. But the level of service of bus is not satisfactory. In addition to the insufficient public transportation system, Dhaka also lacks in infrastructure. On top of that, car ownership is increasing pretty rapidly piling up the traffic congestion. These sum up to a longer travel time; a significant portion of which is spent halting either for congestion or for collecting passengers. This study focuses on the stopping time and the moving time of a bus trip. The discrepancy between demand and supply of public transport is quite severe in Dhaka. When the demand is higher than supply during the peak period or near CBD area, buses get full and over-crowded at earlier stoppages. In such cases, drivers skip the later bus stops where people need to wait longer for bus. But the scene is completely reversed when demand is less than supply. In such cases, drivers tend to wait longer intentionally at the earlier bus stops in the hope of collecting sufficient passengers, termed here as intentional waiting time. This study tries to understand and verify the situation. The result suggest that the intentional waiting time influences the total stopping time significantly. Most of which occurs in the earlier sections of the route and with increasing distance from the origin, the waiting tendency keeps decreasing. The passenger boarding trend follows similar trend. Lack of guideline is one of the main reasons for such behavior and the demand, land use pattern, bus occupancy etc. are some of the major factors influencing intentional waiting to a great extent.
\end{abstract}

Key Words : public transport, travel time, intentional waiting time, bus, Dhaka

\section{INTRODUCTION}

With a population more than 17 million, Dhaka is one of the densest megacities in the world. Being a third world developing country it lacks sufficient infrastructure to serve the transportation need of such huge population. In order to ensure a sustainable transportation system, the role of public transport cannot be overlooked as it can ensure higher passenger- $\mathrm{km}$ with relatively cheaper price by proper planning and management. In spite of being a road based megacity, Dhaka has only $9 \%$ area occupied by roads resulting a poor road network as well as overall transportation system ${ }^{1}$. Regardless of the low quality bus service, $44 \%$ of all household trips is made by bus $^{2)}$ as till date no other mass transit like BRT or metro is available in Dhaka.

The bus services in Dhaka is considered unsatisfactory due to lack of proper planning, management and maintenance. Most of the users are captive user and highly dissatisfied with the service, especially with longer travel time as bus is found to be stopped 

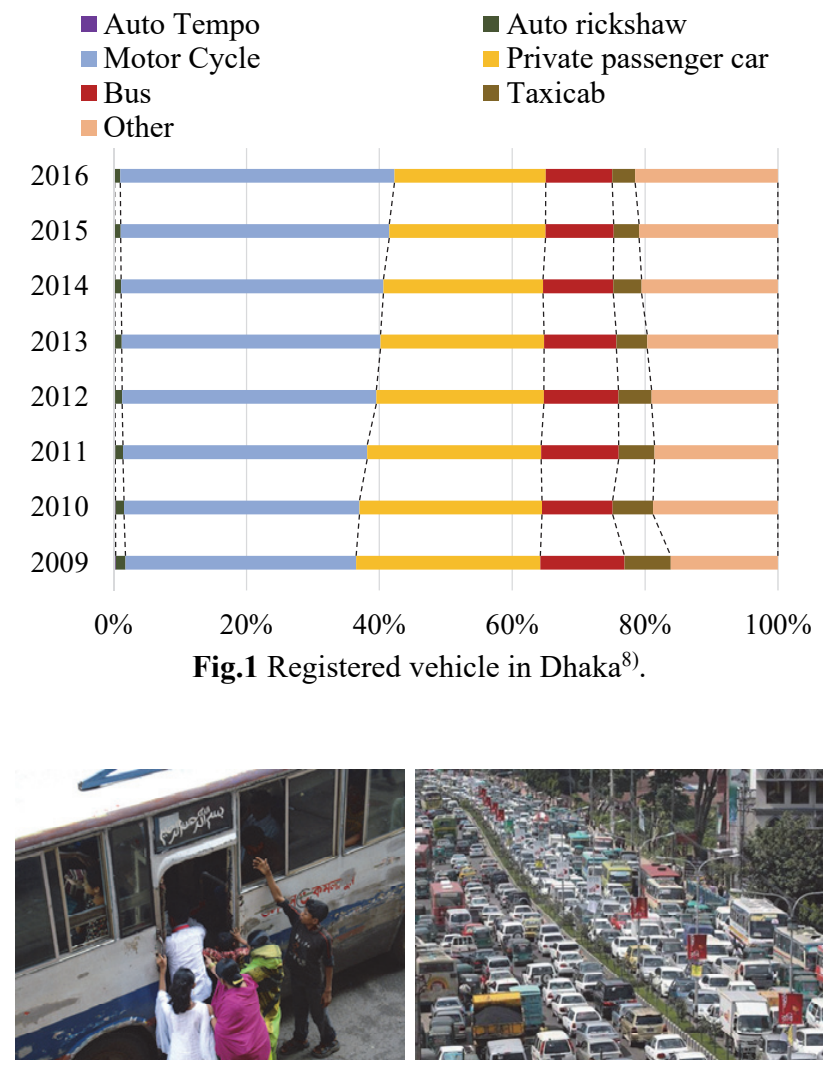

Fig.2 Congestion (left) and passenger collection when demand is low (right).

for a significant time either intentionally for passenger collection or for congestion. This encourages user to shift to other modes like private car, motorbike or taxi whenever affordable.

Mahmud et al. pointed out several deficiencies in bus system of Dhaka from user point of views including lack of passenger information, inadequate bus stops and several problems of bus journey like longer travel time and higher transfer ${ }^{3)}$. Moreover, a poor level of service (LOS) was determined for travel time with by Das. He found the LOS for travel time to be ' $D$ ' and ' $E$ ' for private and government owned bus respectively' ${ }^{4}$. Hence, several delay models has been developed by researchers. The Webster's model ${ }^{5)}$ for estimating the delay incurred by motorists at under saturated signalized intersection was modified by Hoque and Imran for applying in the non-lane based mixed traffic condition ${ }^{6}$. However, their model was applicable for under-saturated traffic condition only. Hadiuzzaman et al. tried to overcome this limitation by developing another delay model that could predict delay for under-saturated as well as over saturated traffic flow at signalized intersection ${ }^{7}$.

Studies related to bus in Dhaka city mainly concerns with intersection delay at signal. Whereas, this study takes into account the intentional delay at bus stop along with the intersection delay.

This paper provides the issues of bus system in
Dhaka and motivation of the study at the beginning followed by the methodology. Showing the analysis and summarizing result, the paper concludes with detailed discussion and direction for future work.

\section{ISSUES WITH CURRENT BUS SYSTEM IN DHAKA}

Being the capital of third world developing country, most of Dhaka's residents are poor. As a result $84 \%$ of households do not have any sort of transport vehicles and depend on public transport. Bus, having the cheapest transport cost per $\mathrm{km}$, comprises only a small proportion of vehicle numbers $\left(11 \frac{1 / 2}{2} \%\right)$ but carries about $77 \%$ of people ${ }^{2}$. Fig. 1 shows the registered motorized vehicle in Dhaka over last 8 years ${ }^{8)}$. As only $5 \%$ of the buses are government owned, the dominating private sector acts like a syndicate providing monopolistic service ${ }^{9}$. As a result in spite of high demand, the monopolistic private sector is not increasing the investment to expand bus fleet in Dhaka for the probability of unprofitable business ${ }^{10}$. Moreover, no guideline as well as bus time schedule is provided by the operator to neither the driver nor the user. In addition to that, no particular service frequency is followed by the operator which leads to bus brunching and a low level of reliability and punctuality of the service.

Bus behavior in Dhaka varies significantly depending on the drivers and conductors operating them. Skipping of stoppages, cutting routes short and dwelling for very long periods at the curb occur unpredictably, although this is more often observed in local buses ${ }^{11}$. These annoyances to travelers can vary between off-peak and on-peak periods, and it is for these reasons that many travelers choose to avoid riding buses ${ }^{12)}$. Mannan et al. found that among other modes bus has the second highest user satisfaction in term of availability after rickshaw ${ }^{13)}$. One of the reasons behind this finding is the intentional waiting by the driver's at the bus stop. Although it increases the total travel time and passengers' on board waiting, sometimes intentional waiting reduces prospective riders waiting time at the bus stop.

While travelling, the waiting time can broadly be classified into two category; one is the time in congestion or signal queue and the other is the time spent intentionally at bus stop to collect more passenger even after regular boarding/alighting is over (Fig.2). Which portion of the waiting time dominates might depend on the location of bus stop, time of the day and passenger on board.

In a growing city like Dhaka longer waiting time could be holding back the economic development. 


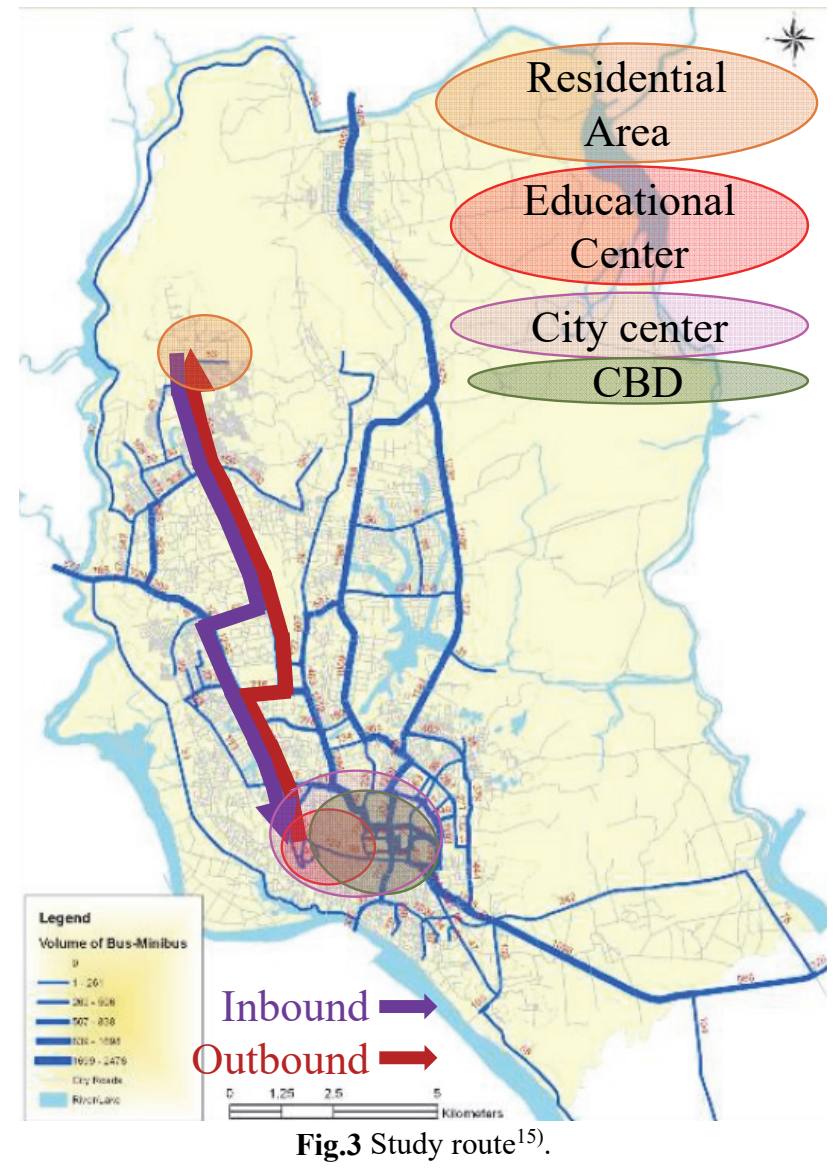

Hence, the aim of this research is to identify the mechanism of intentional waiting time as a component of travel time.

\section{RESEARCH METHOD}

The World Bank report stated "Dhaka is a city stretched to its limit." As showed in Fig.3, the city center is located at South end and the city continued to grow to the North. In Dhaka city, there are 149 bus routes ${ }^{13)}$. Then again most of them are expanded eccentrically in the north-south direction ${ }^{3)}$.

For study purpose, one route of $13.4 \mathrm{~km}$ (Route no: 19/E), shown in Fig.3, connecting the Northern residential zone with the CBD and educational hub at South is selected. Selection was done after a thorough review of OD maps and desire maps of DHUTS $^{14)}$.

Comprehensive field survey was conducted for collecting travel time data along the study route using HOLUX Wireless GPS Logger M-241 for both weekdays (from Saturday to Thursday) and weekend (Friday) (Fig.4). According to the GPS manual, theoretical accuracy of the M-241 is stated at $3 \mathrm{~m}$, but this accuracy can be improved to $2.2 \mathrm{~m}$ (Horizontal deviation 95\% time) when Differential GPS (DGPS)

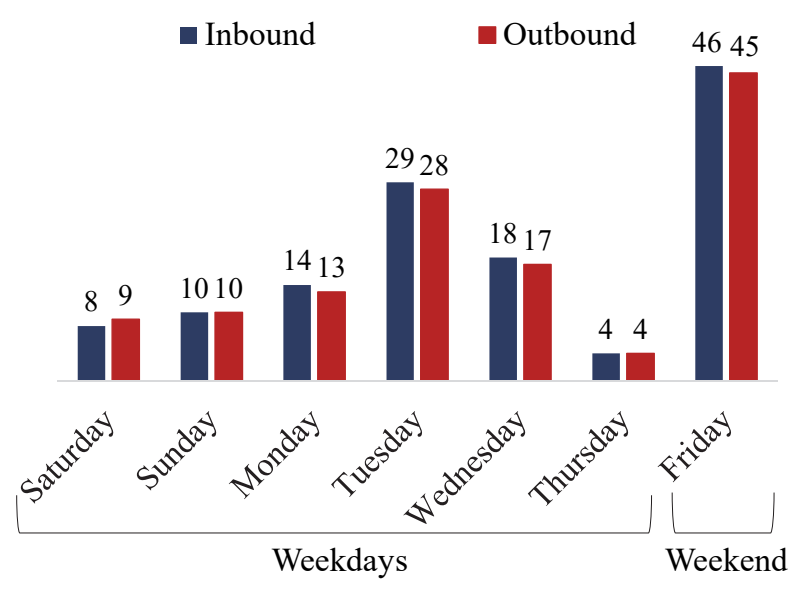

Fig.4 Number of observed trips during survey period.

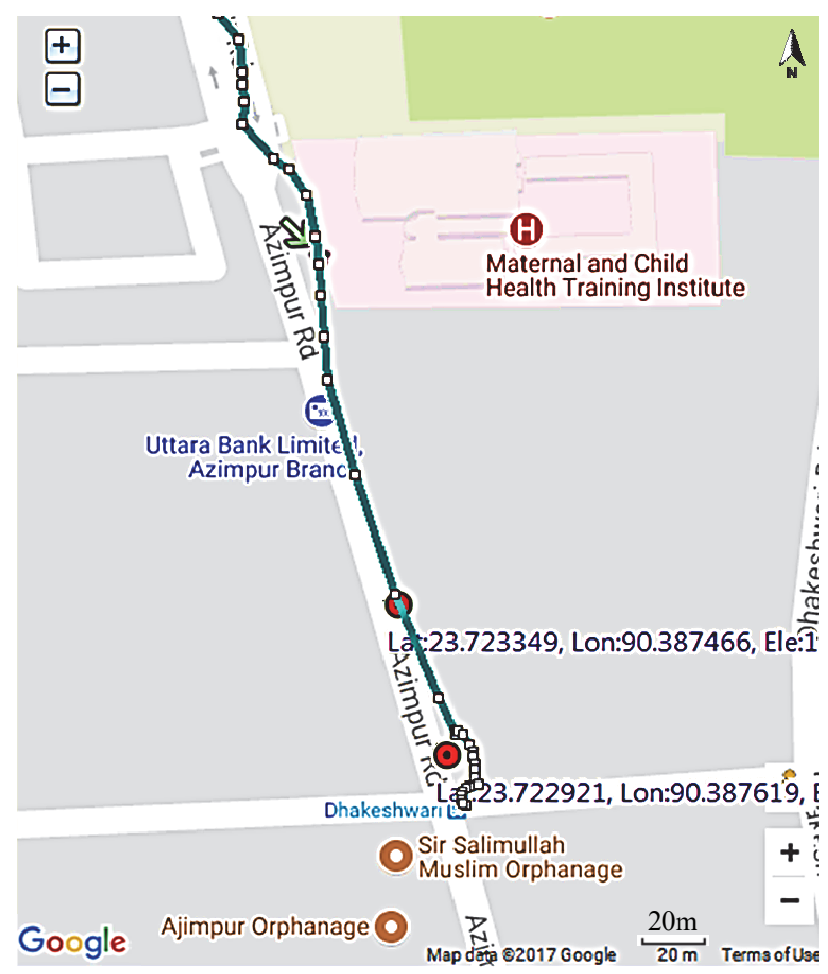

Fig.5 GPS points along the study route on Google map.

is available ${ }^{16)}$. Fig. 5 shows the actual travel path of the bus at the end of inbound trip. Most of the GPS points are located on the physical road and at end when bus comes to stop, the points almost overlap indication a high level of accuracy. This GPS data was processed to calculate distance, moving time, congestion time and intentionally waiting time both at authorized bus stops and intermediate unauthorized locations. To support the data, video clips of random trips were recorded from inside of the bus. Also, the passenger boarding and alighting numbers for each trip were recorded manually.

For the purpose of detailed analysis, the raw data of GPS were transferred in a common '.cvg' file by developing a program using 'Perl Language'. Further 


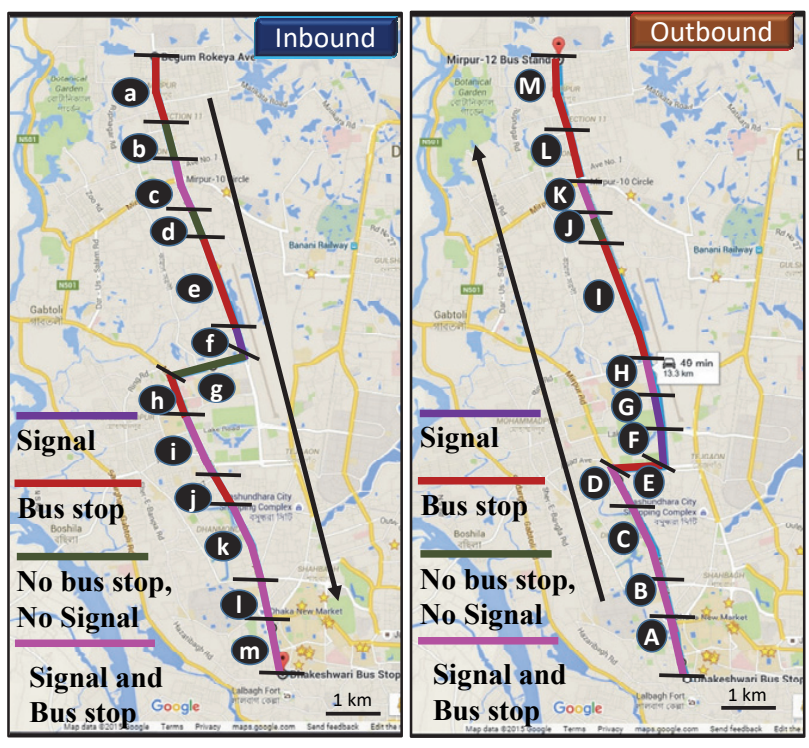

Fig.6 Segments of study routes.

Table 1 Segment details

\begin{tabular}{|c|c|c|c|c|c|c|c|}
\hline \multicolumn{4}{|c|}{ (Inbound) } & \multicolumn{4}{|c|}{ (Outbound) } \\
\hline Segment & $\begin{array}{l}\text { Length } \\
(\mathrm{km})\end{array}$ & $\begin{array}{c}\text { Distance } \\
\text { from } \\
\text { Origin } \\
(\mathrm{km})\end{array}$ & Characteristics & Segment & $\begin{array}{l}\text { Length } \\
(\mathrm{km})\end{array}$ & $\begin{array}{c}\text { Distance } \\
\text { from } \\
\text { Origin } \\
(\mathrm{km})\end{array}$ & Characteristics \\
\hline $\mathrm{a}$ & 1.36 & 1.36 & Bus stop & A & 1.13 & 1.13 & $\begin{array}{c}\text { Bus stop, } \\
\text { Signal }\end{array}$ \\
\hline $\mathrm{b}$ & 0.332 & 1.692 & $\begin{array}{l}\text { No bus stop, } \\
\text { No signal }\end{array}$ & B & 0.731 & 1.861 & $\begin{array}{c}\text { Bus stop, } \\
\text { Signal }\end{array}$ \\
\hline c & 1.22 & 2.912 & $\begin{array}{c}\text { Bus stop, } \\
\text { Signal }\end{array}$ & $\mathrm{C}$ & 1.47 & 3.331 & $\begin{array}{c}\text { Bus stop, } \\
\text { Signal }\end{array}$ \\
\hline d & 0.587 & 3.499 & $\begin{array}{l}\text { No bus stop, } \\
\text { No signal }\end{array}$ & D & 0.969 & 4.3 & $\begin{array}{c}\text { Bus stop, } \\
\text { Signal }\end{array}$ \\
\hline $\mathrm{e}$ & 1.7 & 5.199 & Bus stop & E & 0.949 & 5.249 & Bus stop \\
\hline $\mathrm{f}$ & 0.712 & 5.911 & Signal & $\mathrm{F}$ & 0.674 & 5.923 & Signal \\
\hline $\mathrm{g}$ & 1.4 & 7.311 & $\begin{array}{l}\text { No bus stop, } \\
\text { No signal }\end{array}$ & G & 0.622 & 6.545 & Signal \\
\hline $\mathrm{h}$ & 0.525 & 7.836 & Bus stop & $\mathrm{H}$ & 0.707 & 7.252 & $\begin{array}{c}\text { Bus stop, } \\
\text { Signal }\end{array}$ \\
\hline $\mathrm{i}$ & 1.54 & 9.376 & $\begin{array}{c}\text { Bus stop, } \\
\text { Signal }\end{array}$ & I & 2.399 & 9.651 & Bus stop \\
\hline $\mathrm{j}$ & 0.449 & 9.825 & Bus stop & $\mathrm{J}$ & 0.549 & 10.2 & $\begin{array}{c}\text { No bus stop, } \\
\text { No signal }\end{array}$ \\
\hline $\mathrm{k}$ & 1.386 & 11.211 & $\begin{array}{c}\text { Bus stop, } \\
\text { Signal }\end{array}$ & K & 0.643 & 10.843 & $\begin{array}{c}\text { Bus stop, } \\
\text { Signal }\end{array}$ \\
\hline 1 & 1.05 & 12.261 & $\begin{array}{c}\text { Bus stop, } \\
\text { Signal }\end{array}$ & $\mathrm{L}$ & 1.02 & 11.863 & Bus stop \\
\hline $\mathrm{m}$ & 1.113 & 13.374 & $\begin{array}{c}\text { Bus stop, } \\
\text { Signal }\end{array}$ & M & 1.34 & 12.203 & Bus stop \\
\hline
\end{tabular}

scrutiny was made after that. For determining the distance (d) between two GPS points, Haversine formula (1) was adopted.

$d=2 R \arcsin$

$\times \sqrt{\sin \left(\frac{L a t_{2}-L a t_{1}}{2}\right)^{2}+\cos L a t_{1} \cos L a t_{2} \sin \left(\frac{\text { Lon }_{2}-\text { Lon }_{1}}{2}\right)^{2}}$

where 'Lat' and 'Lon' are their latitude and longitude respectively and ' $R$ ' is the radius of the earth.

For simplification purpose, the vehicle is considered to be stopped when the instantaneous speed is less than $5 \mathrm{~km}$ per hour for 5 seconds or more. Since, waiting time for regular boarding was found to be significantly small compared to intentionally waiting

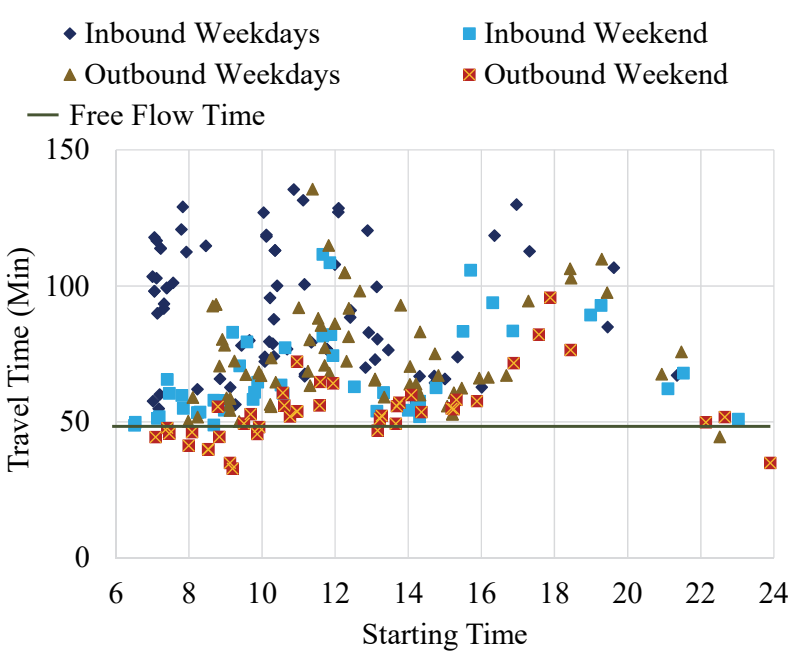

Fig.7 Travel time.

(i.e. negligible), while considering intentional waiting time, this study did not separate time for regular passenger boarding and alighting from extra time waiting to collect more passenger at or apart from designated bus stops. Although, it is highly recommended to consider them separately if the regular boarding is higher. While congestion include waiting time at signalized intersection as well as traffic congestion along the route.

In order to look into deeper image, the entire route was divided into 13 segments based on 4 characteristics like i) presence of bus stop, ii) presence of signal, iii) presence of both bus stop and signal and iv) presence of neither bus stop nor signal (Fig.6) and analyzed for each components separately. Table 1 contains the details of each segment.

\section{DATA ANALYSIS}

\section{(1) Entire trip}

At first, the travel time data was plotted according to starting time of each trip (Fig.7). Although free flow time is 50 minutes, majority of the trips exceed that and most inbound trips exceeds twice the free flow time. The free flow time was estimated by determining the travel time along the route using Google Map and the reliability of the value was checked by driving along the route in early morning with low road traffic volume.

In Weekdays, for inbound trips, it requires less time between 2 p.m. and 4 p.m. While for outbound trip, peak is attained between 11 a.m. to 2 p.m. Also, overall travel time in this direction is relatively low.

Weekend trip pattern is little different from that of weekdays. Unlike weekdays, no significant peak is observed at 8 a.m. for inbound trips; rather the peak is shifted at around 12 p.m. Then again, outbound trip 


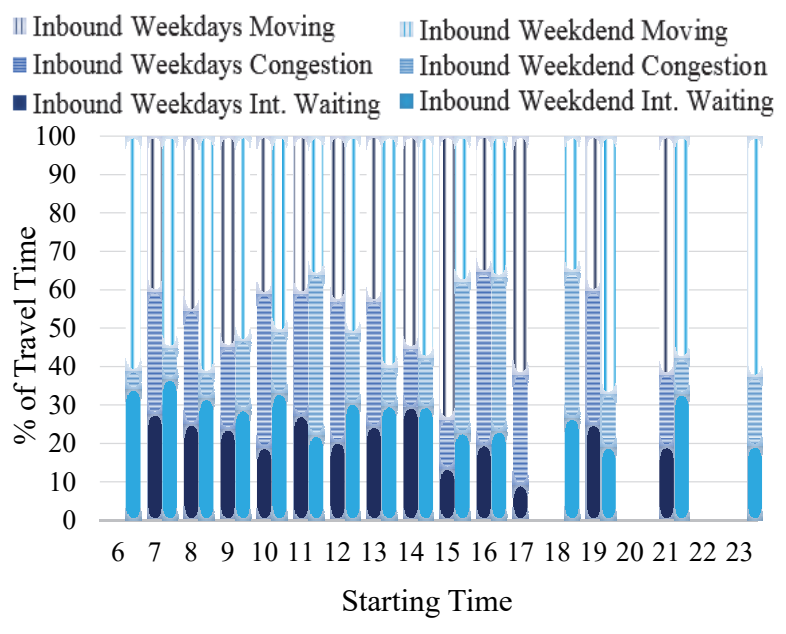

Fig.8 Components of travel time for inbound trip.

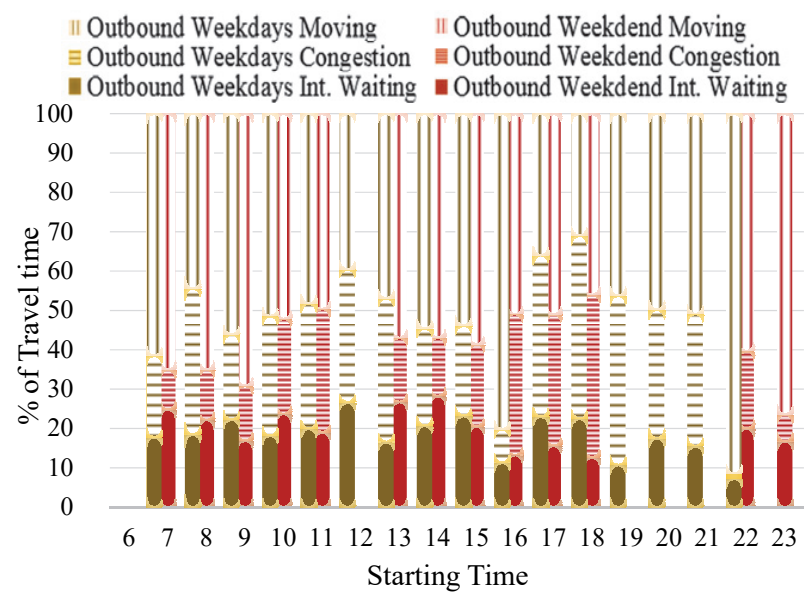

Fig.9 Components of travel time for outbound trip.

reaches its peak at around 6 p.m. when people are returning to their residences. Also, travel time is quite low in weekend than that of weekdays. On weekend, road traffic in early morning and late night along with demand for outbound trips originating from CBD is significantly low. As a result, drivers wait less and can drive at a higher speed, sometimes exceeding speed limit and ignoring traffic signal. Hence, for outbound trip in weekend, some trips are observed to take less than the free flow time at those time.

Although only half of this longer travel time is spent on moving and the rest of it is spent on stopping either for congestion or for intentional waiting. Fig. 8 and Fig.9 shows the ratio of different components of travel time during weekdays and weekend for inbound trips and outbound trips respectively.

In general the congestion is higher during weekdays, whereas intentional waiting time is higher during weekends. Most of the times longer congestion is compensated by waiting less intentionally in order to maintain a stable stopping time ratio of $50 \%$.

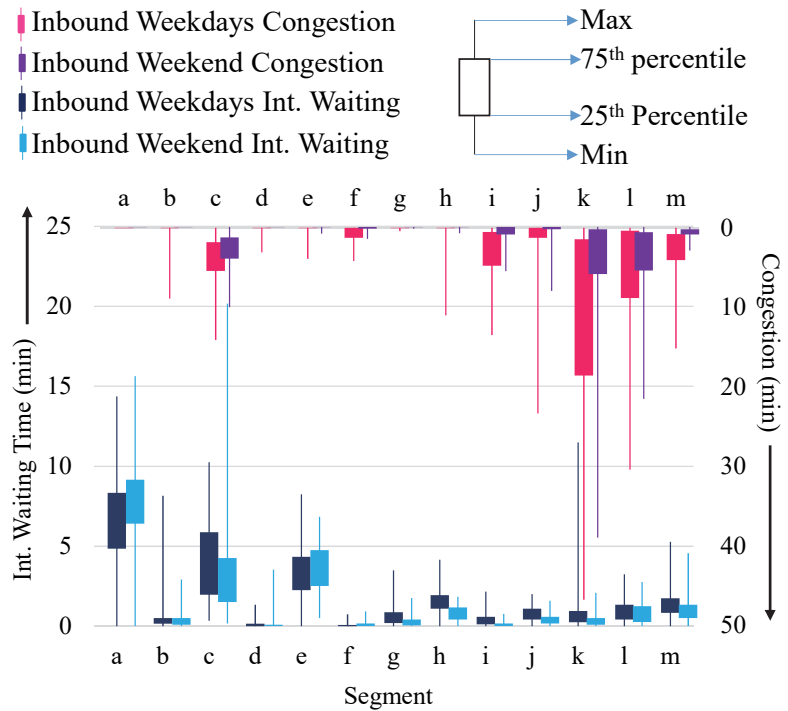

Fig.10 Segmental fluctuation for inbound trip.

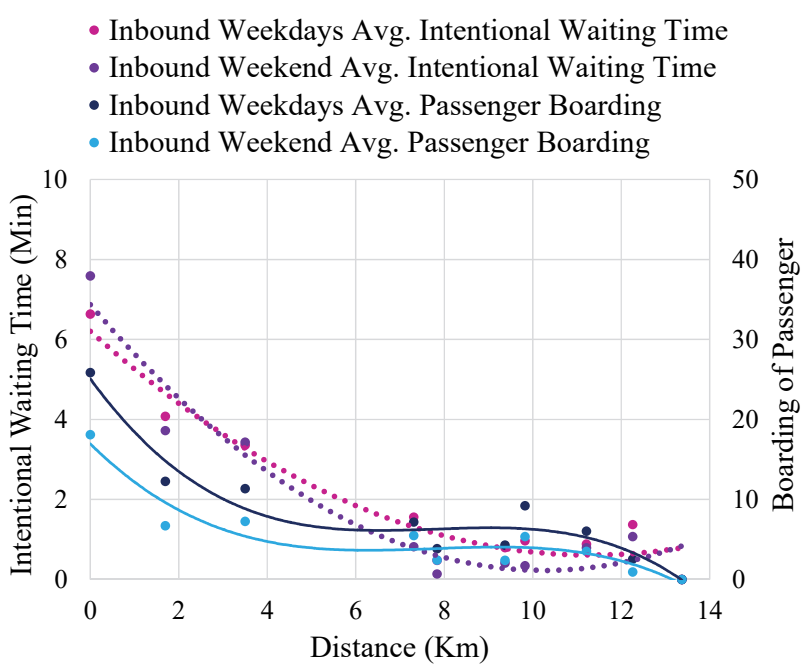

Fig.11 Intentional waiting and boarding for inbound trip.

\section{(2) Segment-wise analysis}

As it is believed that the intentional waiting time as well as congestion is not evenly distributed over the entire route, the effect of them at different segments are identified and analyzed.

\section{a) Segmental detail of inbound trip}

Fig.10 and Fig.11 show segmental variation of intentional waiting time, congestion and boarding of passengers for inbound trips both in weekdays and weekend.

The fluctuation of congestion and intentional waiting time is plotted in Fig.10. The maximum and minimum value is represented at the top and bottom end of the straight line; plus the bottom and the top edge of the rectangle encloses the 25th percentile and 75th percentile value. Also, the larger the width of the rectangle, the larger the fluctuation is.

For intentional waiting time, most fluctuating 


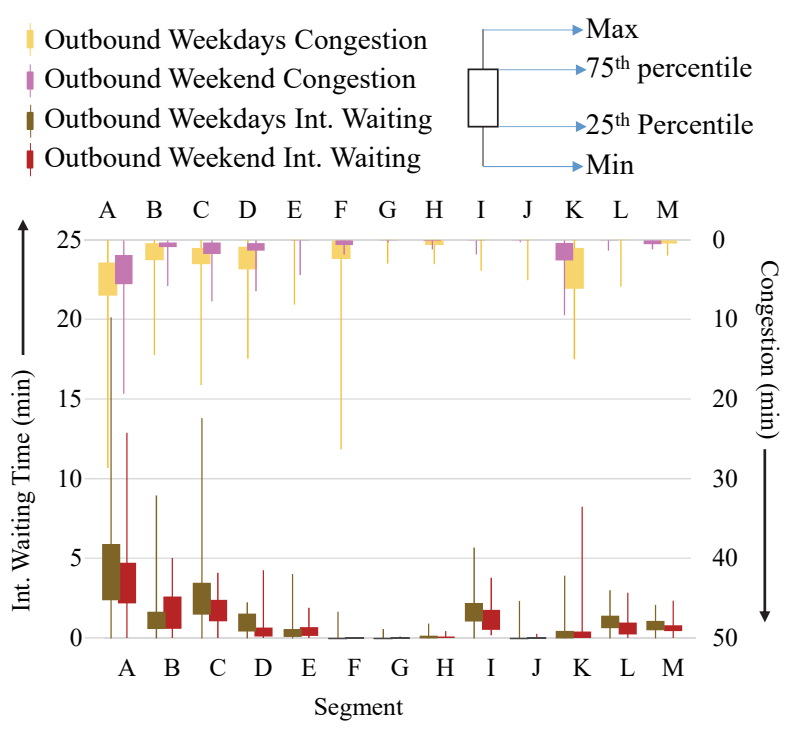

Fig.12 Segmental fluctuation for outbound trip.

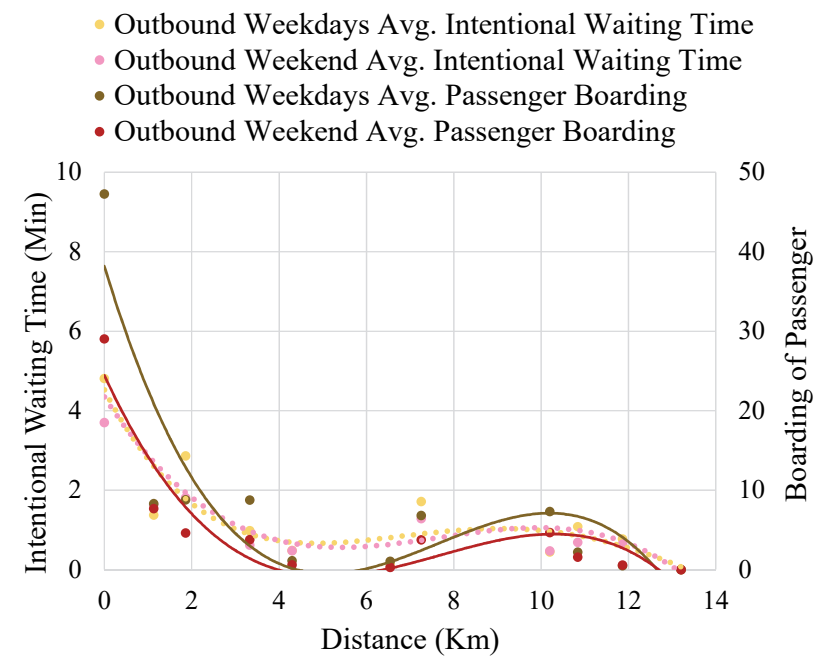

Fig.13 Intentional waiting and boarding for outbound trip.

segments are segment 'a', 'c' and 'e'. Not only has that, these segments had the highest values among all 13 segments. In the maps of Fig.6, these are the segments containing bus stops located in the map at the earlier stage of trip.

On the contrary, congestion is higher at segments ' $\mathrm{k}$ ' and ' $\mathrm{l}$ ' since they are located near CBD. In addition to that, congestion at segment ' $c$ ' along with segments ' $\mathrm{k}$ ' and ' $\mathrm{l}$ ' fluctuates highly as major inter sections are located within them.

The change in intentional waiting time and passenger boarding is shown in Fig.11. Both of them follows similar trend by being maximum at origin and gradually decreasing with distance. In average, bus waits for about 6.6 minutes in order to collect 25 passengers in weekdays at the first bus stop. But on weekend bus collects only 18 passengers even though it waits for 7.6 minutes. This suggests, lower
Table 2 Summery of analyzed data.

\begin{tabular}{|c|c|c|c|c|c|c|c|c|c|}
\hline & & \multicolumn{4}{|c|}{ Inbound } & \multicolumn{4}{|c|}{ Outbound } \\
\hline & & \multicolumn{2}{|c|}{ Weekdays } & \multicolumn{2}{|c|}{ Weekend } & \multicolumn{2}{|c|}{ Weekdays } & \multicolumn{2}{|c|}{ Weekend } \\
\hline & & $\min$ & $\%$ & $\min$ & $\%$ & $\min$ & $\%$ & $\min$ & $\%$ \\
\hline \multirow{3}{*}{$\begin{array}{l}\text { Travel } \\
\text { Time }\end{array}$} & Moving Time & 39 & 46 & 25 & 53 & 49 & 52 & 31 & 60 \\
\hline & Congestion & 24 & 29 & 8 & 17 & 27 & 28 & 10 & 19 \\
\hline & Int. Waiting & 21 & 25 & 14 & 30 & 19 & 20 & 11 & 21 \\
\hline \multicolumn{2}{|c|}{ \# Passenger } & \multicolumn{2}{|c|}{95} & \multicolumn{2}{|c|}{61} & \multicolumn{2}{|c|}{95} & \multicolumn{2}{|c|}{59} \\
\hline
\end{tabular}

demand leads to higher intentional waiting time.

\section{b) Segmental detail of outbound trip}

For outbound trip, the origin is located at CBD with several educational institutions, shopping centers and commercial places resulting a higher demand for outbound trip. Fig.12 shows the fluctuation of intentional waiting time for weekdays and weekend by plotting the maximum, minimum, 25th percentile and 75 th percentile values for each segment.

The intentional waiting time is highest at segments ' $A$ ', 'B' and ' $C$ ' with the maximum fluctuations. Similar to inbound trips, they are also located near origin and contains bus stop. Additionally, significant waiting is observed at segment 'I' with fluctuation as short distance travelers board the bus from the bus stop located here.

Unlike inbound trips, congestion is high at earlier stage of outbound trips since the origin is located near CBD. Congestion at segments ' $A$ ', ' $D$ ' and ' $K$ ' with major intersections is fluctuating remarkably.

Fig.13 shows a similar trend between intentional waiting time and passengers boarding with distance for outbound trips. Similar to inbound trips, the values for outbound trips are maximum at origin and decrease with increasing distance from origin. Although the drops in both values are quite drastic compared to those of inbound trips. Bus collects an average of 47 passengers in less than 5 minutes in weekdays and 29 passengers in less than 4 seconds in weekend which, once again, indicates the higher demand influencing intentional waiting. Also passenger boarding freezes at mid-route. Moreover, a secondary peak near end point is observed due to the boarding of short distance traveler in segment 'I'.

\section{RESULT AND DISCUSSION}

Table 2 summarizes the analyzed data for entire trip. For the same direction of travel, moving time increases by 7 percent points in weekend for both inbound (14 minutes) and outbound trip (18 minutes). Even though for outbound trip, relatively smaller waiting time is observed. Congestion is high and influence the trip behavior to a great extent in weekdays as higher congestion effect is compensated 


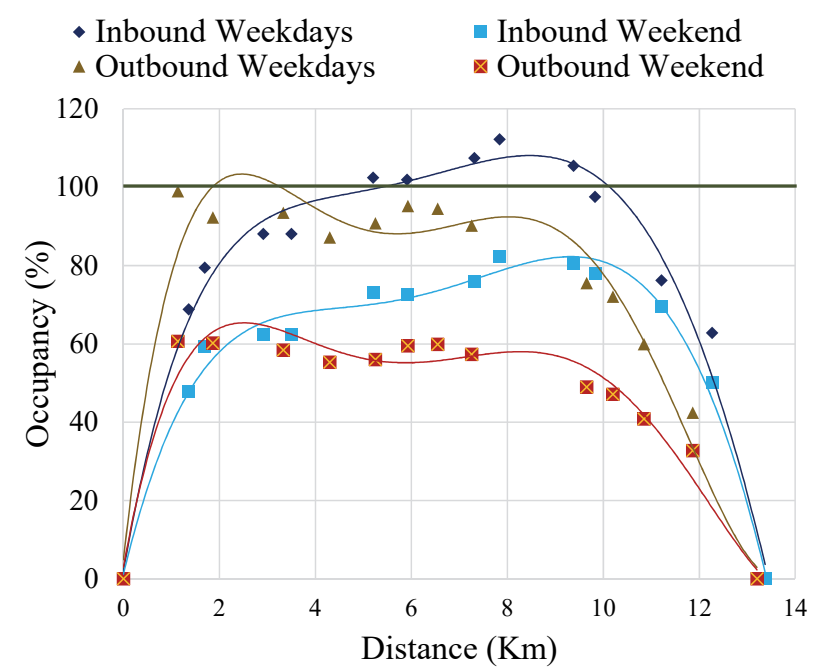

Fig.14 Bus occupancy.

by lower intentional waiting time for having a stable stopping time ratio.

Bus serves an average of 95 passengers per trip in weekdays and 60 passengers in weekend. As a result the intentional waiting has higher ratio of total travel time in weekend compared to weekdays indicating a relation between varying demands throughout the week with waiting time.

Also, land use pattern along the route, especially at the origin and destination influences the intentional waiting time and congestion. CBD has rather higher demand which on one hand creates congestion and on the other hand reduces intentional waiting time.

Fig.14 shows the trend in bus occupancy at the beginning of each segment along the study route (at the beginning of first segment bus is empty). For outbound trip, number of passenger collected during weekdays exceeds bus seat number (36 seats). Presence of standee demotivates drivers to wait intentionally and thus lower intentional waiting time is observed for outbound trips. But for inbound trips, a gradual increase is observed and $100 \%$ occupancy is reached at mid-route. Until that drivers continue to wait intentionally for passenger collection. The occupancy follows similar trend with rather smaller value in weekend as the demand is less.

After investigating each segment closely, it is found that intentional waiting time is maximum at origin and gradually decreases with increasing distance from origin. Also, $70 \%$ of total intentional waiting time is spent before half of the entire route is traveled (Fig.15) and during this period more than $60 \%$ of total passenger for the trip is collected (Fig.16). Moreover, for inbound trip this time is spent within first $45 \%$ of the route length in weekdays and first $30 \%$ of route length in weekend. Due to the lower number of trip produced in weekend, driver

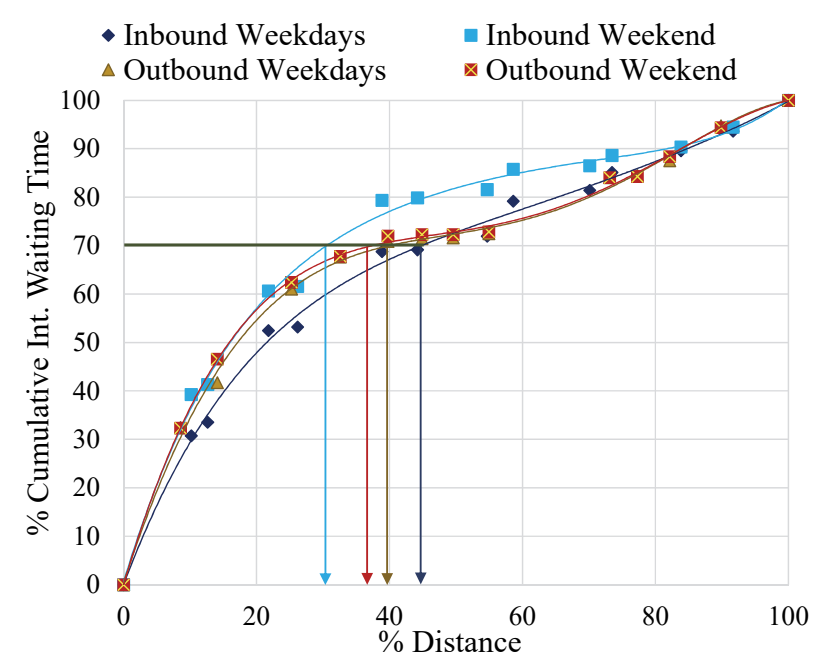

Fig.15 Cumulative waiting time and cumulative distance.

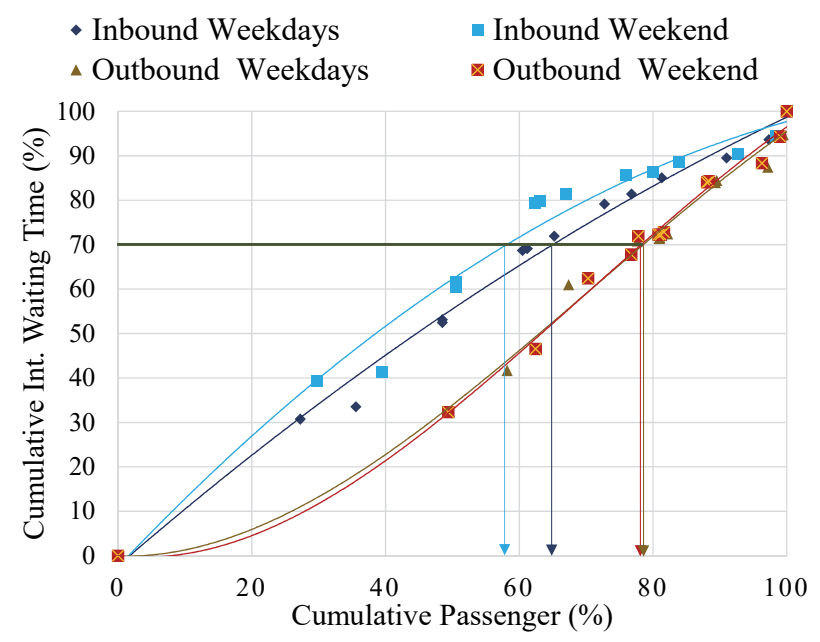

Fig.16 Cumulative waiting time and cumulative passenger.

tends to wait more at earlier bus stops intentionally.

The ratio of time spent in waiting intentionally at bus stop is similar for outbound trips in both weekdays and weekend since the demand is relatively higher near origin compared to other bus stops. But for inbound trips, to collect same number of cumulative percentage of passenger bus needs to wait more on weekend as trip production is lower (Fig.16).

\section{CONCLUSION}

Based on the study, it is clear that bus system of Dhaka is facing severe deficiency in travel time. The unacceptably long travel time is a combined result of road congestion along with intentional waiting for passenger collection. Different factors plays vital role on each of these two stopping time components.

First of all, the demand influence intentional waiting time to a significant extent. As a result, 
weekend has higher intentional waiting for lower demand. Again, higher demand at CBD results in a lower intentional time for outbound trip. Therefore, it can be concluded that due to demand variation not only days of week but also the land use pattern along the route has strong effect on intentional waiting.

Secondly, intentional waiting time is maximum at origin and gradually decreases with distance. Bus stops located at earlier stage of route has higher intentional waiting time with noteworthy fluctuation. As a result, $70 \%$ of intentional waiting time is observed before even completing $50 \%$ of the trip.

Also, bus occupancy and passenger boarding is closely related with intentional waiting. Buses collect passenger by waiting intentionally until occupancy is $100 \%$. Once the occupancy exceeds $100 \%$ intentional waiting drops significantly. For inbound trips on weekdays, occupancy exceeds $100 \%$ within $7 \mathrm{~km}$ to $10 \mathrm{~km}$ of the study route (Fig.14) with a reduced intentional waiting time of less than 1 minute (Fig.11). Usually $70 \%$ of total intentional waiting time is spent in collecting more than first $60 \%$ of passenger per trip.

Since guideline as well as bus time schedule are unavailable, future study need to be carried out for developing operation guideline and bus schedule after detail analysis on demand and policy of operator as well as government. Providing training to driver and monitoring them using manual or in-vehicle GPS to offer reward or penalty for their punctuality might help reducing intentional waiting time.

Since intentional waiting time is a rarely observed phenomenon in many countries, not many study has been conducted on it. This study will serve as a base for future studies in solving this problem.

ACKNOWLEDGMENT: The author would like to extend her heartily thanks to research fellow Dr. Ryo ARYOSHI for his precious time for critical research discussions and insightful comments.

\section{REFERENCES}

1) RMMS : Road maintenance and management system (RMMS), Dhaka City Corporation (DCC), 2004.

2) Louis Berger Group, Inc. \& Bangladesh Consultants Ltd (BCL) : The strategic transport plan (STP) for Dhaka: Ur- ban transport policy, Final report, Dhaka Transport Co-Ordination Board (DTCB), Ministry of Communications, 2005.

3) Mahmud, S., Haque, M. S. and Bashir, G. M. M. : Deficiencies in existing mass transit system in metropolitan Dhaka and improvement options, CODATU XIII, Vietnam, 2008.

4) Das, S. K. : LOS evaluation of improved bus services in Dhaka city, Journal of the East Asia Society fro Transportation Studies, Vol. 4, No. 1, pp. 235-250, 2001.

5) Webster, F. : Traffic signal settings, Road Research Technical Paper, No. 39, 1958.

6) Hoque, M. S. and Imran, M. A. : Modification of Webster's delay formula under non-lane based heterogeneous road traffic condition, Journal of Civil Engineering (IEB), Vol. 35, Issue 2, pp. 81-92, 2007.

7) Hadiuzzaman, M., Rahman, M. M., Hasan, T. and Karim, M. A. : Development of delay model for non-lane based traffic at signalized intersection, International Journal of Civil Engineering (IJCE), Vol. 3, Issue 2, pp. 67-82, 2014.

8) BRTA : Number of registered motor vehicles in Dhaka (year wise), Bangladesh Road Transport Authority, 2016.

9) Rahman, M. S. U. : Service level of public bus in Dhaka city, Bangladesh, 24th World Road Congress (PIARC), Mexico, 2011.

10) Hoque, M. M. and Hossain, T. : Augmentation of mass transit mode in Dhaka, Bangladesh, CODATU XI Conference Paper, Bucarst (Romania), 2004.

11) Katz, D. S. and Rahman, M. M. : Overcrowded buses operating in Dhaka, Bangladesh and the effects on safety, performance, and comfort, Best Practices to Relieve Congestion on Urban Streets in Developing Countries held at IIT Madras, Chennai, India, 2008.

12) Zahir, U. M., Matsui, H. and Fujita, M. : Investigate the effects of bus and passenger arrival patterns and service frequency on passenger waiting times and transit performance of Dhaka metropolitan area, Urban Transport VI: Urban Transport and the Environment for the 21st Century, Vol. 49, pp. 57-64, 2000.

13) Mannan, M. S. and Karim, M. M. : Current State of the Mobility of the Urban Dwellers in Greater Dhaka, 94th Annual Conference and Exhibition of Air and Waste Management Association, Orlando, Florida, USA, 2001.

14) JICA study team : Preparatory survey report on Dhaka urban transport network development study (DHUTS) in Bangladesh, Final report, Dhaka Transport Co-Ordination Board (DTCB), 2010.

15) JICA Project : Number of buses operating in existing bus routes of Dhaka city. Dhaka Transport Coordination Board (DTCB), 2009.

16) HOLUX : HOLUX Wireless GPS Logger M-241 User's Manual, HOLUX Technology Inc. April 2009 ver. C., 2009.

(Received February 24, 2017) 